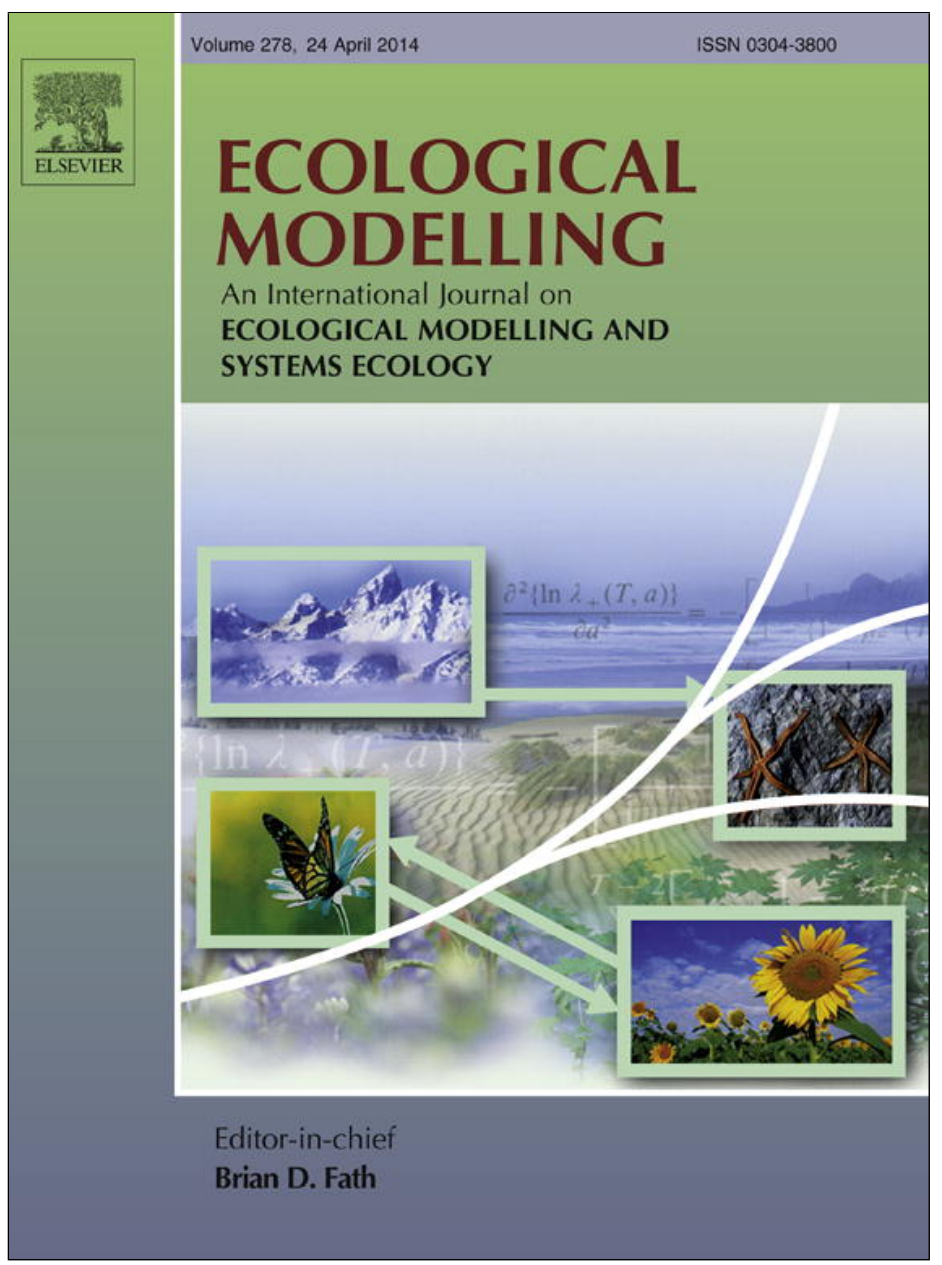

This article appeared in a journal published by Elsevier. The attached copy is furnished to the author for internal non-commercial research and education use, including for instruction at the authors institution and sharing with colleagues.

Other uses, including reproduction and distribution, or selling or licensing copies, or posting to personal, institutional or third party websites are prohibited.

In most cases authors are permitted to post their version of the article (e.g. in Word or Tex form) to their personal website or institutional repository. Authors requiring further information regarding Elsevier's archiving and manuscript policies are encouraged to visit:

http://www.elsevier.com/authorsrights 


\title{
Testing the effects of temporal data resolution on predictions of the effects of climate change on bivalves
}

\author{
Valeria Montalto ${ }^{\mathrm{a}, 1}$, Gianluca Sarà ${ }^{\mathrm{a}, *, 1}$, Paolo Michele Ruti ${ }^{\mathrm{b}, 1}$, \\ Alessandro Dell'Aquila ${ }^{\mathrm{b}, 1}$, Brian Helmuth ${ }^{\mathrm{c}, 1}$ \\ a Dipartimento di Scienze della Terra e del Mare, Università di Palermo, Palermo, Italy \\ ${ }^{\mathrm{b}}$ ENEA, Energy and Environment Modeling Unit, Santa Maria di Galeria, Roma, Italy \\ ${ }^{c}$ Department of Marine and Environmental Sciences, Northeastern University, Boston, MA, USA
}

\section{A R T I C L E I N F O}

\section{Article history:}

Received 27 June 2013

Received in revised form 11 January 2014

Accepted 21 January 2014

Available online 19 February 2014

\section{Keywords:}

Regional climate models

Dynamic Energy Budget models

Darwinian fitness

Marine intertidal zone

Mediterranean

Mytilus galloprovincialis

\begin{abstract}
A B S T R A C T
The spatial-temporal scales on which environmental observations are made can significantly affect our perceptions of ecological patterns in nature. Understanding potential mismatches between environmental data used as inputs to predictive models, and the forecasts of ecological responses that these models generate are particularly difficult when predicting responses to climate change since the assumption of model stationarity in time cannot be tested. In the last four decades, increases in computational capacity (by a factor of a million), and the evolution of new modeling tools, have permitted a corresponding increase in model complexity, in the length of the simulations, and in spatial-temporal resolution. Nevertheless, many predictions of responses such as shifts in range boundaries are often based on coarse spatial and temporal data, for example monthly or yearly averages. Here we model the effects of environmental change on the physiological response of an ecologically and commercially important species of mussel, the fitness of which can have a cascading influence on ecosystem levels. Using a Dynamic Energy Budget (DEB) model integrated with climatic data produced from IPCC-A1B scenarios, we investigated the effect of temporal resolution of physical data on predictions of the growth and reproductive output of the mussel Mytilus galloprovincialis. We ran models using five different temporal scales, 6, 4, 3, 2 and $1 \mathrm{~h}$ (derived by interpolating between $6 \mathrm{~h}$ points), at 5 Italian locations in the Central Mediterranean Sea, for the period ranging from 2006 to 2009. Results from these models were further compared against the results from a DEB model that used hourly environmental data recorded at the five locations as inputs. Model outputs included estimates of life history traits relevant to ecological performance as well as parameters related to Darwinian fitness. Results showed that predictions of maximum theoretical shell length were similar regardless of which source of environmental data was used. However, while the DEB model using 1-h modeled data produced predictions of reproductive output very similar to those obtained using recorded (hourly) environmental data from the same time period, results using coarser resolution modeled data greatly underestimated reproductive output. Thus, the use of modeled weather data can yield predictions similar to those generated from measured data, but only when data are provided at relatively high frequency. Our results suggest that metrics of model skill can diverge significantly when physical outputs of climate models are applied to biological questions, and that the temporal resolution of environmental data can strongly alter predictions of biological responses to environmental change.
\end{abstract}

(c) 2014 Elsevier B.V. All rights reserved.

\section{Introduction}

The temporal and spatial scales over which ecological processes operate are thought to be tightly linked to the intrinsic complexity of the system itself (e.g., Mislan and Wethey, 2011; Wernberg et al., 2012). Considerable research has thus focused on the need to

\footnotetext{
* Corresponding author. Tel.: +39 09123862853; fax: +39 09123862144 E-mail address: gianluca.sara@unipa.it (G. Sarà).

1 All authors contributed substantially to revisions.
}

study ecological processes under different spatio-temporal scales of observation (Broitman et al., 2008; Wiens, 1996), and has emphasized that spatial heterogeneity in the environment at smaller scales can have cascading impacts on ecological interactions operating at much larger scales, and vice versa (Denny et al., 2006; Menge et al., 2011). Surprisingly, while considerable discussion and debate still exist as to the importance of spatial heterogeneity in physical drivers on ecological processes (e.g. Burrows et al., 2009; Denny et al., 2011; Hallett et al., 2004; Wiens, 1996), there has been less of a focus on the potential role of high frequency temporal variability (but see Benedetti-Cecchi, 2003; Denny etal., 2011; Kearaey 
et al., 2012). Several studies have argued that the use of monthly or annual means for predictions of niche dimensions and thus distribution limits may miss important drivers that occur over shorter temporal scales, for example when temporal averaging removes rare but extreme lethal events (e.g., Jentsch et al., 2007). Studies have also suggested that temporal averaging can affect our predictions of sublethal responses such as growth and reproduction. For example, Kearney et al. (2012) modeled physiological responses of lizards and showed that predicted growth and reproductive output varied depending on whether environmental inputs were derived from daily or monthly data. Denny et al. (2009) have argued similarly for the importance of considering the temporal patterning of environmental conditions, and especially the return time of physiologically stressful events. A rectification of processes that occur at the scale of organisms, and the long-term, cumulative effects of these organismal responses on communities and ecosystems, remains one of the biggest challenges facing climate change biologists today (Denny and Helmuth, 2009).

The predicted global warming SRE (Special Report Emissions) scenarios provided by the International Panel on Climate Change (most recently, IPCC, 2007) have represented the core of virtually all studies carried out in climate science and global ecology of the last decade, and have been used to forecast significant (and often detrimental) effects of climate change on natural and human-managed ecosystems, and on the ecosystem services that they provide (Hickler et al., 2012; Mumby et al., 2011; Schweiger et al., 2012). A host of studies have been conducted comparing physiological responses under current conditions, against those in which temperatures are increased by $\sim 2-5^{\circ} \mathrm{C}$, and are intended to reflect conditions in a warmer world. However, as emphasized by Stenseth et al. (2002), organisms are affected not by climate (long-term trends in weather), but rather by weather (short-term changes) that is "trained" by climate. That is to say, the most relevant effect of climate on organisms may not lie in low frequency changes in mean conditions, per se, but rather by how patterns of weather are affected, and how these altered conditions in turn affect organisms (Jentsch et al., 2007). Long-term trends in weather (climate) thus ultimately cause effects at ecological scales because of the cumulative effects of weather on individual organisms, but effective prediction requires that we include (or at least eliminate) any potential influences of higher frequency variability that overlies long-term trends. As a result, an emerging number of studies have explored how environmental "signals" are translated into physiological responses by capturing fine-grained differences in the metabolic processes of organisms through an entire life cycle (e.g. Denny et al., 2006; Helmuth et al., 2010). Still, there remains a major conceptual gap between studies conducted at physiological scales and those conducted over large geographic or long temporal scales. Put simply, we do not necessarily know what comprises "signal" and what is simply "noise".

\subsection{Thermal physiology}

Almost all physiological responses are sensitive to temperature, and the simplest and most frequently used methods for quantifying the relationship between body temperature (BT) and fitness is with a thermal performance curve. A key feature of most performance curves is that they are highly nonlinear. The BT of ectotherms, like most aquatic invertebrates such as bivalves, is driven by the external environment (Lima et al., 2011); in subtidal animals (i.e., always immersed) the body temperature is thus very similar to the temperature of the surrounding water. In some environments water temperature (and hence body temperature) may change slowly, for example over seasonal cycles. Importantly, however, recent studies have shown that such assumptions are not always correct. Nearshore water temperature (and hence body temperature) can exhibit significant hourly fluctuations (several ${ }^{\circ} \mathrm{C}$ ) due to the influence of surface heating from solar radiation, upwelling, or internal wave formation (Leichter et al., 2006; Pfister et al., 2007). Variability in BT in terrestrial and intertidal environments during low tide can be much more extreme, with changes of $20^{\circ} \mathrm{C}$ occurring over a matter of hours. Subsequently, basing estimates of physiological performance on average conditions is therefore very risky, because the relationship between BT and performance can be highly nonlinear. During the normal course of a day for many organisms, their performance will shift with environmental conditions (move along the thermal performance curve) so that relatively small changes in temperature can lead to large changes in performance. Thus, for example, estimates of physiological responses in an animal with a BT fluctuating between 10 and $20^{\circ} \mathrm{C}$ may not be accurately reflected by performance measured at an average temperature of $15^{\circ} \mathrm{C}$. This central thesis suggests that by temporally averaging the drivers of BT, we may be inadvertently biasing the true physiological responses to fluctuating conditions that normally occur in many environments. Quantifying these differences requires an integrative approach that can account not only for rapid changes in physiological performance, but also in the time history of performance.

Whereas the accurate prediction of weather patterns on any particular day at any appreciable time in the future is impossible, climate models can reproduce a coherent chronology (i.e., at 6-h intervals) which represents a possible evolution of the Earth system and thus can effectively overlay "weather" on top of climatic trends. We tested the effect of temporal resolution on correlates of fitness of the Mediterranean blue mussel, Mytilus galloprovincialis (Kearney et al., 2011; Sarà et al., 2011). M. galloprovincialis, native to the Mediterranean, is listed among the 100 of the World's Worst Invasive Alien Species and is a dominant space occupier and structuring species in many rocky shores. It is also an important aquaculture species (Sarà et al., 2012) and worldwide this genus of mussels is worth approximately USD 0.106 billion in annual harvest (DAFF, 2012). Combining a mechanistic approach based on the Dynamic Energy Budget model (DEB; Kooijman, 2010) and seawater temperatures projected by the PROTHEUS climate coupled model (Artale et al., 2010), specifically developed for the Mediterranean Sea under an A1B scenario (Carillo et al., 2012; Dell'Aquila et al., 2011), we examined how two temporal scales of output from a climatic model - two models with the same accuracy (skill) when based on comparisons of physical environmental data - may result in different expressions of model skill when evaluated using physiological metrics.

\section{Materials and methods}

Mechanistic (process-based) predictive models such as DEB theory (Kooijman, 2010) represent a potentially valuable and reliable tool for studying physiological and ecological responses in the context of climate change, particularly when coupled with measurements of the physical environment at appropriate spatial and temporal scales (Kearney et al., 2012; Sarà et al., 2011, 2012, 2013a, 2014). A major advantage of these models is their ability to predict not only patterns of mortality, but also sub-lethal responses such as changes in growth, maximum size, and reproductive output. In these models, all aspects of organismal metabolic machinery are generally rate-based, implying that all predictions of organis mal processes will be a direct function of physiological rates; i.e. they are not dimensionless (sensu Kooijman, 2010). DEB is able to quantify the principal life history traits (e.g. size, time to puberty and number of eggs) as a function of the real amount of energy 
available in the food and the current (or predicted through climate scenarios) body temperature. Through this approach, it is possible to provide accurate predictions of life history characteristics of organisms within the context of the microclimate where they really live. Using the mussel $M$. galloprovincialis as a model species, we first compared the output of a DEB model using data recorded in situ by buoys to that generated using model A1B predictions (hindcasts) at the same temporal resolution (created by interpolation between 6 -h data points outputted by the model). Once the similarity of output between these two models was verified, we compared the model outcomes from five different temporal scales $(6,4,3,2$ and $1 \mathrm{~h})$ using the A1B dataset only.

\section{Theory}

\subsection{Dynamic Energy Budget (DEB) theory and parameters}

DEB captures the whole-organism bioenergetics connecting individual behaviors to population growth (Kooijman, 2010). The most important factors driving the metabolic machinery in organisms are food and body temperature. Only a few concepts are needed to explain the mechanistic nature of a DEB model (Kooijman, 2010): (1) energy and matter assimilated from food are assumed to be proportional to the organisms' surface area following a type II functional response (Holling, 1959); (2) they are directed to a reserve (e.g., fat, protein); (3) the reserve flux is mobilized according to the $\kappa$-rule (i.e., a fixed fraction $(\kappa)$ is allocated to growth and somatic maintenance while the remaining $1-\kappa$ is allocated to maturity maintenance, maturation or reproduction); (4) maintenance has priority over growth and growth ceases when all reserves are used for somatic maintenance (Fig. 1). Before running the DEB model, we needed to obtain functioning parameters of the target species by integrating experimental and mathematical procedures. In this case, M. galloprovincialis parameters were obtained experimentally or from the literature (Sarà et al., 2012, 2011).

\subsection{Study area, and environmental parameters}

A major strength of DEB theory is an ability to track the dynamics of development, growth and reproduction as an explicit function of temperature and food availability (Kearney and Porter, 2006; Kearney et al., 2011; Sarà et al., 2013a,b). DEB models were run by inputting these variables as forcing drivers of life history of mussels throughout the central Mediterranean Sea (Fig. 2). In particular, we performed DEB simulations using food and water temperature datasets from 5 sites around the Italian Peninsula, from the northernmost Gulf of Tigullio (LAT $\sim 44^{\circ}$; LONG $\sim 9^{\circ}$ ) up to the southernmost Sicilian Strait (LAT $\sim 35^{\circ}$; Lampedusa) to the eastern part of the Adriatic Sea (LONG $\sim 19^{\circ}$ ). We ran DEB models simulating subtidal conditions as previously done in Sarà et al. (2011, 2012, 2013a,b), thus assuming that BT approximated seawater temperature (Lima et al., 2011). Models were run with seawater temperatures (01/01/2006-31/12/2009) for 5 Italian locations of the Central Mediterranean Sea (Lampedusa, Palermo, Bari, Genova and Trieste; Fig. 2), at five different time scales. Hourly seawater temperature measurements were obtained from buoys maintained by the Italian Institute of Environmental Research (ISPRA; http://www.mareografico.it/; buoys are located close to harbor areas of each site, far less than few $\mathrm{Km}$ from areas over which we run IPCC scenarios). Modeled seawater temperatures were obtained from PROTHEUS. In running DEB models, we used a DEB model subroutine developed by Kearney (2012) for which structural volume, reserve density and reserve allocated to reproduction can be estimate every hour, as long as the body temperature estimates and the thermal constraints

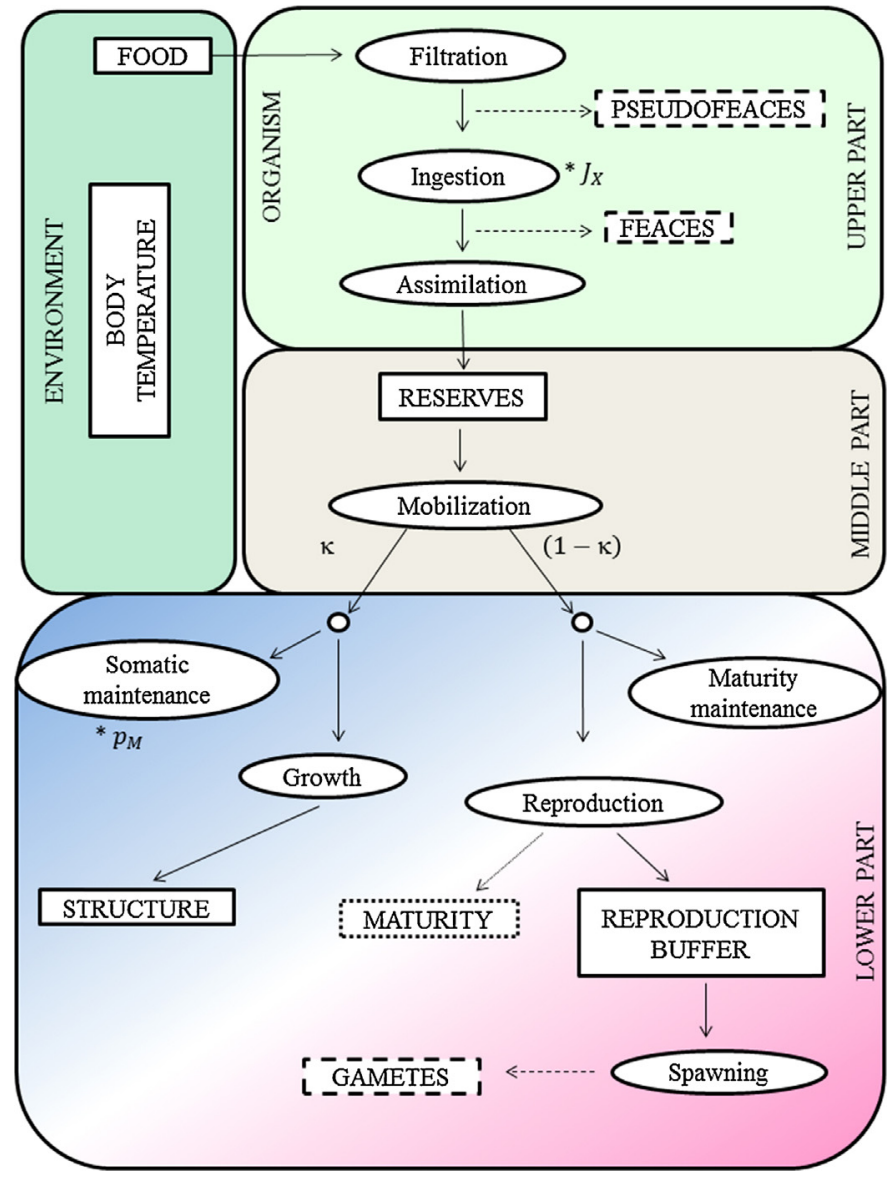

Fig. 1. Schematic representation of a standard DEB model (Kooijman, 2010) describing the fluxes of energy through an organism coming from the environment. The "Upper part" deals with feeding process that describes how energy coming from food is stored as metabolites (e.g. stored proteins, lipids, carbohydrates); Middle part: reserve in which the energy is first stored then made available for direct use following the $\kappa$-rule; Lower part: energy coming from reserve is allocated to maintenance and transformed into structure (i.e. growth) and offspring (i.e. reproduction). *indicates physiological parameters modified according to the different time-scale models; $J_{X}=$ maximum ingestion rate, $\mathrm{Jh}^{-1}, p_{M}=$ somatic maintenance costs, $\mathrm{Jh}^{-1}$ (from Sarà et al., 2014).

of activity periods (i.e. physiological performances) are known. Because the DEB model as it was conceived was based on hourly rates, to adapt the DEB routine (Kearney, 2012; Kearney et al., 2012) to the different time-scale datasets, we adjusted two physiological parameters responsible for the net budget of energy available to organisms: ingestion rates and the somatic maintenance costs.

In a DEB context, the maximum surface area-specific ingestion rate (the DEB parameter called $\left\{j_{x m}\right\}$ ) can be estimated by using the following formula: $\left\{j_{x m}\right\}=J_{X} /\left(f V^{2 / 3}\right)$, where $J_{X}$ is the maximum ingestion rate $\left(\mathrm{Jh}^{-1}\right), f$ is the scaled functional response (dimensionless, ranging from $0-1)$ and $V\left(\mathrm{~cm}^{3}\right)$ is the structural body volume expressed as the cube of the shape coefficient and the organism's shell length. Volume-specific somatic maintenance costs (the DEB parameter called $\left[\dot{p}_{M}\right]$ ) are usually estimated by scaling the amount of energy needed to fuel basal metabolism $\left(\dot{p}_{M}\right)$ with the organisms' volume, such as $\left[\dot{p}_{M}\right]=p_{M} / V$; in order to include the effect of body temperature on individuals physiological performance, for both parameters the same temperature correction factor was applied, i.e. through the Arrhenius relationship (e.g. see Kooijman, 2010; Sarà et al., 2013a).

These parameters are usually estimated on an hourly basis and in this study were converted from a per hour to a 2, 3, 4 and 6 hobasis 


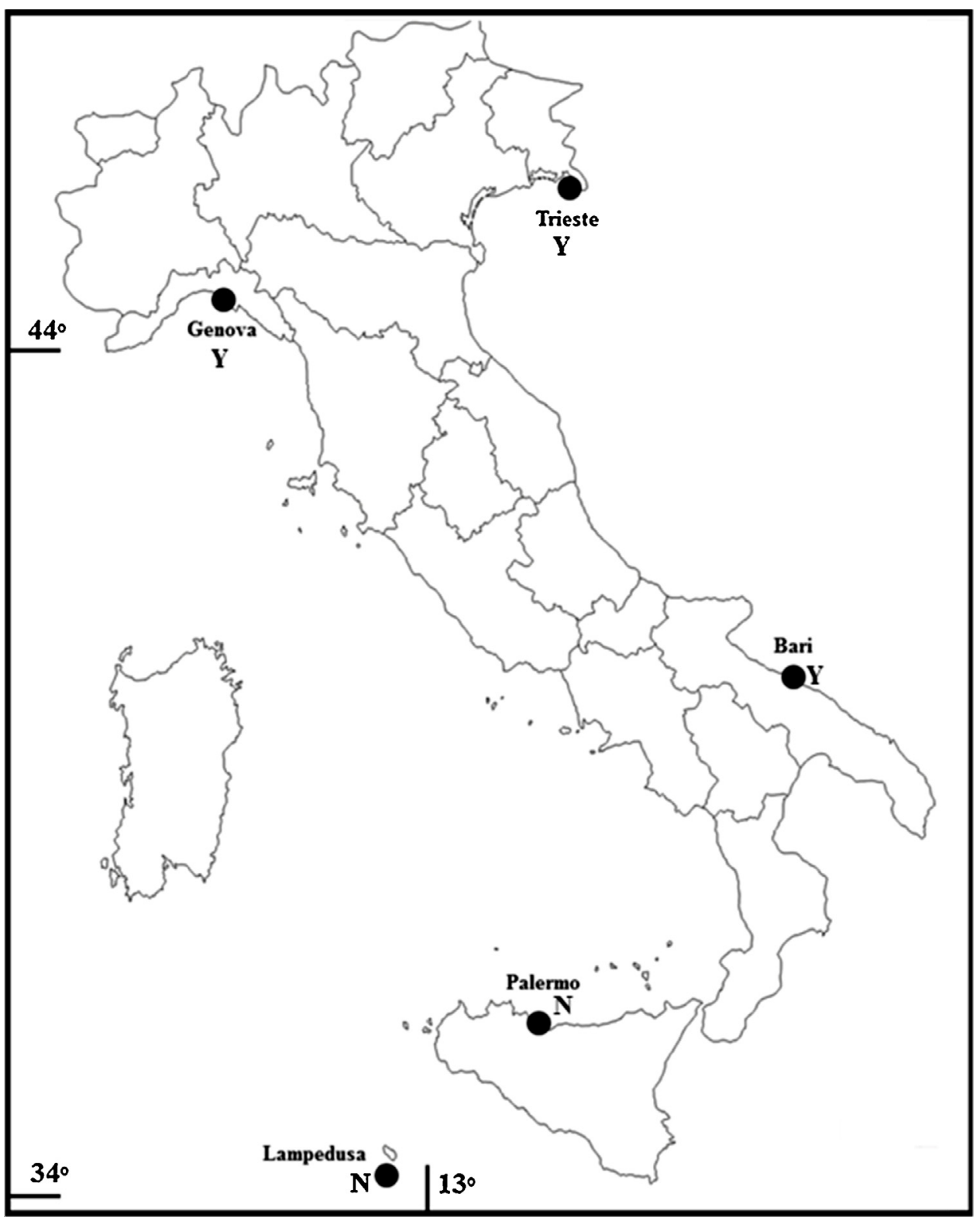

Fig. 2. Map reporting all sites considered in this study; Occ=ascertained presence $[\mathrm{Y}]$ or absence $[\mathrm{N}]$ through literature (Sarà et al., 2014).

by simply multiplying parameters obtained on an hourly basis by a corresponding factor of two, three, four and six, respectively; this strategy allowed us to use the same model to compare outputs from input data at several temporal resolutions without changing any other parameters. Modeled temperature outputs were originally performed on a $6 \mathrm{~h}$ basis with a total of 4 points per day (00:00, 06:00, 12:00 and 18:00). Since the main goal of this work was to compare the effects of adoption of different temporal scales on predictions of bivalve fitness, we performed a linear interpolation of temperature data to obtain hourly data from the $6 \mathrm{~h}$ estimates. Accordingly, we expanded the dataset from 6 to $1 \mathrm{~h}$ scale (i.e., from 4 to 24 points per day) starting from the original $6 \mathrm{~h}$ data source, and then used the hourly estimates as described above. Interpolations were performed by employing the ZOO package (Z's Ordered Observations) included in the $\mathrm{R}$ statistical software available at http://www.r-project.org/. In addition to temperature, DEB models also require available food levels as inputs. Adopting an approach similar to that of several other recent DEB studies (Kearney et al., 2011; Sarà et al., 2013a, 2013b, 2012, 2011) of bivalves, we used chlorophyll-a (chl-a) from satellite imagery to estimate food density available to suspension feeders. Monthly data for $c h l-a\left(\mu \mathrm{g} \mathrm{L}^{-1}\right)$ were obtained from January 1998 to December 2007 (i.e., 120 pointmonths) from the EMIS website (http://emis.jrc.ec.europa.eu). We downloaded data from a horizontal grid spacing of $30 \mathrm{~km}$ positioned on the sea around every ISPRA oceanographic station. Areas were $\sim 10 \mathrm{~km}$ from the coast to avoid the interference of reflectance due to the presence of the landmass. Notably, we recognized that varying the temporal resolution of available food could potentially have effects akin to those of varying temperature. However, we held food relatively constant in order to independently examine the effects of temporal variability in temperature. Simulations were run for 4 years, which is considered the mean life span for $M$. galloprovincialis at each location under subtidal conditions. Model outputs included: (i) the maximum theoretical total shell length $(\mathrm{TL}, \mathrm{cm}$ ) reached by mussels at 48 months from settlement, (ii) maturation time (days), (iii) the number of reproductive events (RE, $n$ ) throughout the simulated 4-year period and (iv) total reproductive output (TRO, $n$ ) i.e., the number of eggs produced per biomass unit 
(dry weight) throughout 4 years. In two cases model outputs predicted the absence of mussels due to complete reproductive failure (as in Sarà et al., 2013b, 2011). We therefore adopted the method described by Buckley et al. (2010) and Manel et al. (2001), comparing presence and absence of animals predicted by the model to observations in the field. We estimated the sensitivity index (\% proportion of true presences correctly predicted throughout the 5 study sites) and the specificity index (\%, proportion of true absences correctly predicted throughout the 5 sites of this study). Model performance (\% true) was tested combining the first two metrics by calculating the percentage of all cases that were correctly predicted (true presences plus true absences divided by total cases).

\section{Results}

Outcomes of our simulations showed differences in life history traits and fitness of M. galloprovincialis throughout the study area when predicted using buoy data (Table 1 ) and with model data at the five different temporal scales (Table 1). Results suggested no remarkable differences between model outputs generated using buoy data and the hourly A1B dataset. All five model outputs predicted the presence of mussels at 3 out of 5 sites, i.e., in Bari, Genova and Trieste (Table 1 ). In these sites, mussels usually reached larger sizes. At the other two sites, while mussels were predicted to grow to small size, a complete reproductive failure was predicted (see below). Models using either hourly data or multiples were highly consistent with results generated using water temperature data in estimating the total length everywhere throughout the study area. For example, in Lampedusa, models estimated approximately the same total length (ranging from 1.36 to $1.47 \mathrm{~cm}$ ) and in Trieste, Genova and Bari there was a negligible difference (an average of $0.5 \mathrm{~cm}$ in four years as estimated on 1 and $6 \mathrm{~h}$ basis, respectively). In contrast, remarkable differences were found in predictions of metrics of reproductive output such as number of reproductive events, total number of eggs and time to reach the puberty depending on the input dataset used (Table 1). The number of reproductive events was substantially underestimated by the $4 \mathrm{~h}$ and the $6 \mathrm{~h}$ models as compared to the $2 \mathrm{~h}$ and to the other two, $1 \mathrm{~h}$ models at the sites where the mussel was predicted to be present (Bari, Genova and Trieste). Indeed the use of coarser resolutions (i.e. 4 and $6 \mathrm{~h}$ ) returned a number of reproductive events about $60 \%$ less than those predicted at $1 \mathrm{~h}$ basis using either A1B or measured buoy temperatures, respectively (Table 1).

The total number of eggs followed the same pattern in that both the 4 and $6 \mathrm{~h}$ models predicted a total lifetime production of 9606 and 474,784 eggs in Genova and Trieste, respectively compared to 36,000 and 2,420,000 eggs as predicted using the $1 \mathrm{~h}$ data. In addition for those sites, the amount of eggs produced per life span differed even when 2 and $3 \mathrm{~h}$ models were used; indeed the total production in Bari, Genova and Trieste, was estimated about 560,000 ( $2 \mathrm{~h}$ model) and 428,000 ( $3 \mathrm{~h} \mathrm{model)} \mathrm{compared} \mathrm{to} \mathrm{over}$ 860,000 eggs predicted using $1 \mathrm{~h}$ input data (on average 35 and $50 \%$ less; Table 1 ).

None of the models predicted the presence of Mytilus in Lampedusa and Palermo due to reproductive failure. This result was consistent with an observed absence of mussels from these sites, and with the time to reach puberty as estimated on 1$\mathrm{h}$ basis ( $\sim 1400$ days, or $\sim 4$ years which means that mussels should never reproduce in 4 years thus preventing stable populations from forming). In contrast, the time to reach puberty predicted by the models built using different temporal resolution data was faster than that predicted by either of the hourly models (Table 1).

\section{Discussion}

The application of a mechanistic approach based on ecophysiological bioenergetic models allowed us to explore the influence of temporal resolution of climatic data on predictions of growth performance and fitness in bivalves. At all scales of simulations adopted here (from 1 to $6 \mathrm{~h}$ ), the mechanistic model was able to confidently predict ( $100 \%$ according to our sensitivity analysis; Manel et al., 2001) the likelihood of species occurrence in the central and northern Italian sites (Bari, Genova and Trieste). Here, environmental conditions, as expressed by temperature and food density, are very likely to allow this species to persist over time. This is supported by the massive presence of shellfish farms in those areas, which are the primary areas of Mytilus cultivation in the Mediterranean Sea with almost 40,000 t of commercial mussels produced per year (FAO, 2000). The models were also able to specifically predict the absence of mussels at southern latitudes such as Palermo and Lampedusa, which corresponded to field observations (Sarà et al., 2011). Our results strongly suggest that at the sites examined the scale of input data had little effect on coarse predictions of presence and absence (e.g. reproductive vs nonreproductive populations), at least when comparing predictions made using different temporal resolution data. However, identifying the correct scale was critical for disentangling the reproductive dynamics of M. galloprovincialis, which may in turn have significant impacts at higher ecological levels, and may have long-term consequences for population growth and viability. Moreover, the sites explored here represented an extreme range of habitat suitability. It is therefore perhaps not surprising that all models predicted absence due to reproductive failure at low food sites. Identifying correct scales may be critical at sites where conditions of food, temperature or other environmental variables change from optimal to suboptimal.

In some cases, therefore, it could be argued that "getting the details right" in terms of growth and reproduction may be unimportant, if the focus is on lethal conditions that set ranges. This assumption however belies the observation that not all range edges are set by the same mechanism, in either space or time. For example, Woodin et al. (2013) argue that while lethal limits serve as effective indicators of where Mytilus live on the east coast of North America, it does not work when the same model is applied to Europe. Here, they argue, limits are more likely set by longer-term physiological stress. Nevertheless, to fully understand the potential of the mechanistic approach, as suggested in a recent review by Monaco and Helmuth (2011), we must be able to correlate local environmental variability to individual sub-lethal responses (e.g. growth and reproductive reduction). Such a framework may be critical for forecasting ecosystem-level responses to climate change, especially when examining structuring species, keystone species and ecosystem engineers (Violle et al., 2012). Specifically, such predictions may be crucial when attempting to anticipate rapid phase shifts (tipping points) which can likely occur even in the absence of large changes in the environment due to nonlinearities in how organisms are affected by physical processes (Monaco and Helmuth, 2011). In a broader context for example, the ability to mechanistically provide estimates of commercial body size in animals such as M. galloprovincialis, would be a vital tool for the optimizing shellfish production (Sarà et al., 2012). From our distribution map based on DEB modeling, we could identify more suitable areas where mussels may reach larger body sizes in Italian sectors of the Mediterranean Sea, and thus provide guidance as to where to launch more profitable economic investments in aquaculture (sensu Sarà et al., 2012). This could also have important ecological implications, since aquaculture is considered the best candidate globally to reduce the ecological impact of artisanal fish-c ery and promote the reversion of eutrophication effects restoring 
Table 1

Main outcomes obtained from DEB models using current buoy hourly data (ISPRA) and five different temporal resolution input data derived using an IPCC-A1B scenario throughout the Italian locations.

\begin{tabular}{|c|c|c|c|c|c|c|c|c|}
\hline & LT & MT & \# eggs & RE & LT & MT & \# eggs & RE \\
\hline & \multicolumn{4}{|c|}{ Trieste } & \multicolumn{4}{|c|}{ Genova } \\
\hline Current ISPRA & 6.73 & 316 & $1,837,054$ & 9 & 2.52 & 821 & 27,700 & 6 \\
\hline IPCC-A1B $1 \mathrm{~h}$ & 7.15 & 300 & $2,426,425$ & 9 & 2.56 & 803 & 36,151 & 7 \\
\hline IPCC-A1B $2 \mathrm{~h}$ & 7.15 & 150 & $2,123,408$ & 7 & 2.60 & 402 & 24,923 & 6 \\
\hline IPCC-A1B $3 \mathrm{~h}$ & 7.16 & 100 & $1,606,856$ & 5 & 2.60 & 268 & 18,800 & 4 \\
\hline IPCC-A1B $4 \mathrm{~h}$ & 7.15 & 75 & $1,339,391$ & 4 & 2.60 & 201 & 18,797 & 3 \\
\hline \multirow[t]{2}{*}{ IPCC-A1B $6 \mathrm{~h}$} & 7.26 & 50 & 474,784 & 2 & 2.76 & 130 & 9,606 & 2 \\
\hline & \multicolumn{4}{|c|}{ Bari } & \multicolumn{4}{|c|}{ Palermo } \\
\hline Current ISPRA & 3.28 & 703 & 88,102 & 6 & 1.63 & 1421 & 0 & 0 \\
\hline IPCC-A1B $1 \mathrm{~h}$ & 3.53 & 665 & 118,961 & 7 & 1.68 & 1421 & 0 & 0 \\
\hline IPCC-A1B $2 \mathrm{~h}$ & 3.53 & 332 & 92,145 & 6 & 1.68 & 711 & 0 & 0 \\
\hline IPCC-A1B $3 \mathrm{~h}$ & 3.53 & 222 & 88,071 & 5 & 1.68 & 474 & 0 & 0 \\
\hline IPCC-A1B $4 \mathrm{~h}$ & 3.53 & 166 & 55,465 & 4 & 1.68 & 356 & 0 & 0 \\
\hline IPCC-A1B $6 \mathrm{~h}$ & 2.71 & 136 & 13,789 & 3 & 1.58 & 243 & 0 & 0 \\
\hline \multicolumn{9}{|c|}{ Lampedusa } \\
\hline Current ISPRA & 1.47 & 1383 & 0 & 0 & & & & \\
\hline IPCC-A1B $1 \mathrm{~h}$ & 1.47 & 1383 & 0 & 0 & & & & \\
\hline IPCC-A1B 2 h & 1.47 & 692 & 0 & 0 & & & & \\
\hline IPCC-A1B $3 \mathrm{~h}$ & 1.47 & 462 & 0 & 0 & & & & \\
\hline IPCC-A1B 4 h & 1.47 & 346 & 0 & 0 & & & & \\
\hline IPCC-A1B $6 \mathrm{~h}$ & 1.36 & 243 & 0 & 0 & & & & \\
\hline
\end{tabular}

LT = Total shell length after 4 years, $\mathrm{cm}$; MT = Maturation time, days; $\#$ eggs = total number of eggs produced by a single individual per life span; RE = Number of reproductive events in 4 years.

water quality in degraded estuaries, ponds and lagoons (Jackson et al., 2001).

Individual life history traits are the key-aspects to be investigated for the understanding of ecological processes at the upper levels of ecosystems (Miller et al., 2011; Violle et al., 2012). Here, our mechanistic model was able to accurately work at different temporal scales adopted to describe life history traits of our mussels. Model fallacy was nearly nil in dealing with predictions of total length maximally reachable under every local condition (i.e., the Von Bertalanffy infinite length), throughout the study area. Only a very small deviation across all models tested was observed, when considered on an annual basis. The confidence of models in correctly assessing the importance of various functional traits of organisms, offers opportunities probably never imagined only ten years ago in studying the growth performance of ectotherms. The similarity in predictions of maximum body size between all three models suggests that these observed differences in predicted reproduction are truly the result of differences in the temporal resolution of the input data, and not an artefact of the modeling design. Indeed, in studying the reproductive outputs, we showed that all three main reproductive estimates (number of reproductive events, time of maturation and total number of eggs) resulted underestimated as much as the temporal resolution is coarser. Our results suggest that even minor temporal averaging can have significant impacts on predictions of reproduction, likely because of the nonlinearities inherent in the species thermal performance curve.

We expect that the use of temporal averaging over even broader scales (e.g. monthly or seasonally) would lead to even greater mismatches between environmental drivers and physiological responses (Potter et al., 2013). Such a result is similar to what has previously been shown in terrestrial environments (Reynolds-Hogland and Mitchell, 2007; Dillon et al., 2010; Mislan and Wethey, 2011; Kearney et al., 2012) where it was demonstrated that reproductive output is the life history trait most affected by the application of data at an incorrect temporal scale. Such a fact relies on assumptions of the DEB model that explain the interactive effects of temperature and food availability on fecundity (Kooijman, 2010; Jager, 2012), such as the possibility that by using coarser-resolution data, the model does not accurately capture reserve dynamics. In other words, while growth describes continuous processes that necessarily tend to reach an asymptote within the same species (i.e. the individual maximum habitat size; Sarà et al., 2013a) under the same environmental conditions, reproductive events are estimated to occur when a certain threshold and environmental triggers take place (e.g. Kooijman, 2010). The use of coarser resolution input data may have failed in adequately meeting reserve dynamics, probably filling it above this critical threshold (Kearney, 2012). Thus, increasing temporal resolution may increase the likelihood of capturing instances when the reserve is empty, i.e. the number of reserve depletion events = reproductive events (spawning). In addition, as suggested by Kearney et al. (2012), the adoption of incorrect temporal scales in predicting the future effect of climate drivers, could have a major effect on all species with limited ability to thermoregulate, such as the bivalves examined here. Ectotherms represent more than $90 \%$ of the life on the Earth, and any underestimation of thermal effect on their metabolic machinery and life cycle could lead to incorrect future predictions dealing with the biodiversity. Thus in a context of climate changes studies, identifying the necessary optimal resolution will require serious effort on several fronts to increase our understanding of how organisms will respond to environmental change (e.g. Potter et al., 2013); a lack of sufficient knowledge regarding sublethal responses to climate change could thus potentially be the Achilles heel of current research aimed at studying the likely effects of future climatic scenarios on ecological responses (sensu Kearney et al., 2012).

An important consideration, and one that has not been addressed here, is whether frequency distributions of climatic drivers alone are sufficient to predict physiological response, or whether the effects of time history (i.e. the return time of physiologically stressful but nonlethal events) play an important role (Denny and Helmuth, 2009; Denny et al., 2009; Kearney et al., 2012). Thus, for example, an extreme ("stressful") day followed by several mild ("unstressful") days may have different physiological implications than a period of repeated extreme events, or long periods of moderate stress (Kearney et al., 2012). Future studies of such interactions are therefore critical (Denny and Helmuth, 2009). Mechanistic models appear to be perhaps the best tool that the ecological community has in hand to provide accurate predictions of ecological responses in a changing world. Models let cuis 
put the information that we have together in a rational, orderly way to make predictions about the future; as an alternative, "without them, all we can do is guess" (ad litteram Donald De Angelis in Pennisi, 2012).

\section{Author's contribution}

VM: performed modeling work, analyzed output data and writing, GS: conceived the idea and writing; PR: performed climate modeling work; AD: performed climate modeling work; $\mathrm{BH}$ : conceived the idea and writing.

\section{Acknowledgements}

This paper has been in part sustained by the project "TETRIS-PRIN 2010-2011" funded by the Italian Ministry of Research and University (MIUR). The research leading to these results has received funding from the European Union Seventh Framework Programme FP7/2007-2013 under grant agreement no. 282746 (IMPACT2C project) and under grant agreement no. 265192 (CLIMRUN project). BH was supported by NSF grant OCE0926581 and NASA grant NNX11AP77G. GS supported a Visiting Scholar Award 2012 made by the Office of the Provost at the University of South Carolina. This is contribution number 306 from the Northeastern University Marine Science Center.

We thank Alessandro Rinaldi for his help during modeling phase and Allison Matzelle and Mackenzie Zippay who provided critical suggestions during the course of the project. We are especially grateful to Mike Kearney to have supported our effort in DEB modeling, providing us with the first Excel routine to calculate DEB models and also to Bas Kooijman who was essential for inspiring our DEB work along the course of last 5 years.

\section{References}

Artale, V., Calmanti, S., Carillo, A., Dell'Aquila, A., Herrman, M., Pisacane, G., et al., 2010. An atmosphere-ocean regional climate model for the Mediterranean area: assessment of a present climate simulation. Clim. Dyn. 35, 721-740.

Benedetti-Cecchi, L., 2003. The importance of the variance around the mean effect size of ecological processes. Ecology 84, 2335-2346.

Broitman, B.R., Mieszkowska, N., Helmuth, B., Blanchette, C.A., 2008. Climate and recruitment of rocky shore intertidal invertebrates in the Eastern North Atlantic. Ecology 89, S81-S90.

Buckley, L.B., Urban, M.C., Angilletta, M.J., Crozier, L.G., Rissler, L.J., Sears, M.W., 2010. Can mechanism inform species' distribution models? Ecol. Lett. 13, 1041-1054.

Burrows, M.T., Harvey, R., Robb, L., Poloczanska, E.S., Moore, P., Leaper, R., et al., 2009. Spatial scales of variance in abundance of intertidal species: effects of region, dispersal mode, and trophic level. Ecology 90, 1242-1254.

Carillo, A., Sannino, G., Artale, V., Ruti, P.M., Calmanti, S., Dell'Aquila, A., 2012. Steric sea level rise over the Mediterranean Sea: present climate and scenario simulations. Clim. Dyn., http://dx.doi.org/10.1007/s00382-012-1369-1.

Dell'Aquila, A., Calmanti, S., Ruti, P., Struglia, M.V., Pisacane, G., Carillo, A., et al., 2011. Impacts of seasonal cycle fluctuations in an A1B scenario over the EuroMediterranean. Clim. Res., http://dx.doi.org/10.3354/cr01037.

Denny, M.W., Helmuth, B., 2009. Confronting the physiological bottleneck: a challenge from ecomechanics. Integr. Comp. Biol. 49, 197-201

Denny, M.W., Miller, L.P., Harley, C.D.G., 2006. Thermal stress on intertidal limpets: long-term hindcasts and lethal limits. J. Exp. Biol. 209, 2420-2431.

Denny, M.W., Hunt, L.J.H., Miller, L.P., Harley, C.D.G., 2009. On the prediction of extreme ecological events. Ecol. Monogr. 79, 397-421

Denny, M.W., Dowd, W.W., Bilir, L., Mach, K.J., 2011. Spreading the risk: small-scale body temperature variation among intertidal organisms and its implications for species persistence. J. Exp. Mar. Biol. Ecol. 400, 175-190.

Department of Agriculture, Forestry and Fisheries (DAFF), 2012. Biodiversity Risk and Benefit Assessment, www.daff.gov.za/doaDev/fisheries/03_areasofwork/ Aquaculture/BIODIVERSITY/M.\%20galloprovincialis\%20BRBA\%2012.12.12.pdf

Dillon, M.E., Wang, G., Huey, R.B., 2010. Global metabolic impacts of recent climate warming. Nature 467, 704-706.

Food and Agriculture Organization, 2000. Fishery Statistics: Principal Producers in 1998. FAO Department, Available at: http://www/fao.org/statist/ summtab/aq_a5.asp

Hallett, T.B., Coulson, T., Pilkington, J.G., Clutton-Brock, T.H., Pemberton, J.M., Grenfell, B.T., 2004. Why large-scale climate indices seem to predict ecological processes better than local weather. Nature 430, 71-75.
Helmuth, B., Broitman, B.R., Yamane, L., Gilman, S.E., Mach, K., Mislan, K.A.S., et al., 2010. Organismal climatology: analyzing environmental variability at scales relevant to physiological stress. J. Exp. Biol. 213, 995-1003.

Hickler, T., Vihland, K., Feehan, J., Miller, P.A., Smith, B., Costa, L., et al., 2012. Projecting the future distribution of European potential natural vegetation zones with a generalized, tree species-based dynamic vegetation model. Glob. Ecol. Biogeogr. 21, 50-63.

Holling, C.S., 1959. Some characteristics of simple types of predation and parasitism. Can. Entomol. 91, 385-398.

International Panel on Climate Change, 2007. In: Solomon, S., Qin, D., Manning, M., Chen, Z., Marquis, M., Averyt, K.B., Tignor, M., Miller, H.L. (Eds.), Contribution of Wzzorking Gzzroup I to the Fourth Assessment Report of the Intergovernmental Panel on Climate Change. Cambridge University Press, Cambridge, UK/New York, Available at: http://www.cambridge.org/features/ earth_environmental/climatechange/wg1.htm

Jackson, J.B.C., Kirby, M.X., Berger, W.H., Bjorndal, K.A., Botsford, L.W., Bourque, B.J., Bradbury, R.H., Cooke, R., Erlandson, J., Estes, J.A., Hughes, T.P., Kidwell, S., Lange, C.B., Lenihan, H.S., Pandolfi, J.M., Peterson, C.H., Steneck, R.S., Tegner, M.J., Warner, R.R., 2001. Historical overfishing and the recent collapse of coastal ecosystems. Science 293 (3), 629-638.

Jager, T., 2012. Making Sense of Chemical Stress Application of Dynamic Energy Budget Theory in Ecotoxicology and Stress, http://www.debtox.info/book.php

Jentsch, A., Kreyling, J., Beierkuhnlein, C., 2007. A new generation of climate change experiments: events, not trends. Front. Ecol. Environ. 5, 365-374.

Kearney, M.R., 2012. Metabolic theory, life history and the distribution of a terrestrial ectotherm. Funct. Ecol. 26, 167-179.

Kearney, M., Porter, W.P., 2006. Ecologists have already started rebuilding community ecology from functional traits. Trends Ecol. Evol. 21, 481-482.

Kearney, M., Simpson, S.J., Raubenheimer, D., Helmuth, B., 2011. Modelling the ecological niche from functional traits. Philos. Trans. R. Soc. Lond. Biol. 365, 3469-3483.

Kearney, M.R., Matzelle, A., Helmuth, B., 2012. Biomechanics meets the ecological niche: the importance of temporal data resolution. J. Exp. Biol. 215, 922-933.

Kooijman, S.A.L.M., 2010. Dynamic Energy Budget Theory for Metabolic Organisation, 3rd ed. Cambridge University Press, Cambridge.

Leichter, J.J., Helmuth, B., Fischer, A.M., 2006. Variation beneath the surface: quantifying complex thermal environments on coral reefs in the Caribbean, Bahamas and Florida. J. Mar. Res. 64, 563-588

Lima, F.P., Burnett, N.P., Helmuth, B., Kish, N., Aveni-Deforge, K., Wethey, D.S., 2011. Monitoring the intertidal environment with biomimetic devices. In: Cavrak, M. (Ed.), Biomimetic Based Applications. InTech, New York NY, pp. 499-522, ISBN: 978-953-307-195-4

Manel, S., Williams, H.C., Ormerod, S.J., 2001. Evaluating presence-absence models in ecology: the need to account for prevalence. J. Appl. Ecol. 38, 921-931.

Menge, B.A., Gouhier, T.C., Freidenburg, T., Lubchenco, J., 2011. Linking long-term, large-scale climatic and environmental variability to patterns of marine invertebrate recruitment: toward explaining "unexplained" variation. J. Exp. Mar. Biol. Ecol. 400, 236-249.

Miller, A.D., Roxburgh, S.H., Shea, K., 2011. How frequency and intensity shape diversity-disturbance relationship. Proc. Nat. Acad. Sci. 108, 5643-5648.

Mislan, K.A.S., Wethey, D.S., 2011. Gridded meteorological data as a resource for mechanistic macroecology in coastal environments. Ecol. Appl. 21, 2678-2690.

Monaco, C.J., Helmuth, B., 2011. Tipping points, thresholds, and the keystone role of physiology in marine climate change research. Adv. Mar. Biol. 60, 123-160.

Mumby, P.J., Iglesias-Prieto, R., Hooten, A.J., Sale, P.F., Hoegh-Guldberg, O., Edwards, A.J., et al., 2011. Revisiting climate thresholds and ecosystem collapse. Front. Ecol. Environ. 9, 94-95.

Pennisi, E., 2012. News computational biology virtual hot spots. Science 336, $172-174$.

Pfister, C.A., Wootton, J.T., Neufield, C.J., 2007. Relative roles of coastal and oceanic processes in determining physical and chemical characteristics of an intensively sampled nearshore system. Limnol. Oceanogr. 52, 1767-1775.

Potter, K.A., Woods, H.A., Pincebourde, S., 2013. Microclimatic challenges in global change biology. Global Change Biol. 19, 2932-2939.

Reynolds-Hogland, M.J. Mitchell, M.S., 2007. Three axes of ecological studies: matching process and time in landscape ecology. In: Bissonette, J.A., Storch, I. (Eds.), Temporal Dimensions of Landscape Ecology: Wildlife Responses to Variable Resources. Springer, New York, pp. 174-194.

Sarà, G., Kearney, M., Helmuth, B., 2011. Combining heat-transfer and energy budget models to predict local and geographic patterns of mortality in Mediterranean intertidal mussels. Chem. Ecol. 27, 135-145.

Sarà, G., Reid, G., Rinaldi, A., Palmeri, V., Troell, M., Kooijman, S.A.L.M., 2012. Growth and reproductive simulation of candidate shellfish species at fish cages in the southern Mediterranean: Dynamic Energy Budget (DEB) modelling for integrated multi-trophic aquaculture. Aquaculture 324-325, 259-266.

Sarà, G., Palmeri, V., Montalto, V., Rinaldi, A., Widdows, J., 2013a. The parameterisation of bivalve functional traits in a context of mechanistic ecophysiological Dynamic Energy Budget model. Mar. Ecol. Progr. Ser. 480, 99-117.

Sarà, G., Palmeri, V., Rinaldi, A., Montalto, V., Helmuth, B., 2013b. logical invasions in marine habitats through eco-physiological models: a study case with the bivalve Brachidontes phara $19,1235-1247$

Sarà, G., Rinaldi, A., Montalto, V., 2014. Thinking beyond orga based bioenergetic mechanistic approach for predictions of $\mathrm{f}$. marine organisms. Mar. Ecol. (in press). 
Schweiger, O., Heikkinen, R.K., Harpke, A., Hickler, T., Klotz, S., Kudrna, O. et al., 2012. Increasing range mismatching of interacting species under global change is related to their ecological characteristics. Glob. Ecol. Biogeogr. 21 88-99.

Stenseth, N.C., Mysterud, A., Ottersen, G., Hurrell, J.W., Chan, K.S., Lima, M., 2002. Ecological effects of climate fluctuations. Science 297, 1292-1294.

Violle, C., Enquist, B.J., McGill, B.J., Jiang, L., Albert, C.H., Hulshof, C., et al., 2012. The return of the variance: intraspecific variability in community ecology. Trends Ecol. Evol. 27, 244-252.
Wernberg, T., Smale, D.A., Thomsen, M.S., 2012. A decade of climate change experiments on marine organisms: procedures, patterns and problems. Glob. Change Biol. 18, 1491-1498.

Wiens, J.A., 1996. Wildlife in patchy environments: metapopulations mosaics and management. In: McCullough, D. (Ed.), Metapopulations and Wildlife Conservamanagement. In: McCullough, D. (Ed.), Metapopu
tion. Island Press, Washington, DC, pp. 53-84.

Woodin, S.A., Hilbish, T.J., Helmuth, B., Jones, S.J., Wethey, D.S., 2013. Climate change, species distribution models, and physiological performance metrics: predicting when biogeographic models are likely to fail. Ecol. Evol. 3, 3334-3346. 